\title{
Research on training model of the optoelectronic major university student's innovative ability under the guidance of TRIZ theory
}

Qing Wang, Wenbo Xiao, Chao Yan, Shengpeng Wan, Xingdao $\mathrm{He}$

Qing Wang, Wenbo Xiao, Chao Yan, Shengpeng Wan, Xingdao He, "Research on training model of the optoelectronic major university student's innovative ability under the guidance of TRIZ theory," Proc. SPIE 10452, 14th Conference on Education and Training in Optics and Photonics: ETOP 2017, 104526S (16 August 2017); doi: 10.1117/12.2270039

Event: 14th Conference on Education and Training in Optics and Photonics, ETOP 2017, 2017, Hangzhou, China 


\title{
Research on Training Model of the Optoelectronic Major University Student's Innovative Ability under the Guidance of TRIZ Theory
}

\author{
Wang Qing*, Xiao Wenbo*, Yan Chao, Wan Shengpeng, He Xingdao \\ The National Physics Experiment Teaching Center, Nanchang Hangkong University ,Nanchang \\ 330063,China
}

\begin{abstract}
With the rapid development of optoelectronic technology, it is more and more difficult for the students to grasp the related knowledge, and to have innovative thinking and innovative ability. The reason is that the students can't understand that knowledge easily; In addition, the students find it is hard to find innovative projects to enhance themselves. This paper summarizes a teaching approach to impart innovative knowledge. The following is: help students to establish the following thinking, "according to the difficulties encountered in photovoltaic technology, identify and find the key problem, $\rightarrow$ converted into the standard TRIZ problem $\rightarrow$ find their own solutions. The results show that this approach plays an important role in cultivating students' creative thinking.
\end{abstract}

Keywords: TRIZ theory, innovative thinking, ability practice

\section{INTRODUCTION}

The education of creation and innovation of college students has become the focus and hot topic of the higher institutions and the whole society ${ }^{[1,2,3]}$. The Chinese Ministry of Education and the State Council issued many guiding documents on training creative and innovative talents in recent years. In 2015, the State Council General Office of China issued implementation opinion on deepening reform of creation and innovation education in higher institutions ${ }^{[4]}$. The document makes clear that the local authorities and universities should establish the advanced creation and innovation education idea, strengthen creation and innovation education and cultivate the students' creative and innovative spirit and ability.

However, there are some serious problems on the creation and innovation education of photoelectric undergraduates $[5,6,7]$. First, the students can not timely master and understand the latest optoelectronic expertise due to technology upgrading. Second, the students can not apply the combination of their knowledge to practice since they haven't got acquainted with advanced projects of photoelectric characteristics. For this, based on TRIZ method, we explored a pattern of innovative ability cultivation for college students of optoelectronic major. In this pattern, the creation, innovation and education are the three principle factors. The pattern broke through the overall effect of interrelations and interactions of the three principle factors. The TRIZ theory is the theory of inventive problem solving, which is one of the greatest inventions in the 20th century. The theory successfully reveals the inherent law and principle of inventions. It is a complete theoretical system that is used widely in Fortune 500 companies and multinational companies.

In 2008, the China's Ministry of Science and Technology, the National Development and Reform Commission, the Departments of Education and the Association for Science and Technology jointly issued the several opinions on strengthening work of innovation methods, which expressed to generalize TRIZ-based innovation method. For this, we built innovation education to the following.

\section{BUILDING CONTENT SYSTEM OF INNOVATION EDUCATION}

Based on TRIZ innovation method, the content system of innovation education will be built on the platform of the national physical experimental demonstration center and guided by solar unmanned aircraft project. The project is one of creation and innovation projects. The objective of building content system of innovation education is to develop photoelectric major students' spirit and ability of innovation. Improved trinity training model of the talents in practice will be achieved. The trinity includes to supported with the platform, take method as the think tank and guided by the project. In the platform, experimental demonstration motivates students. The fundamental, comprehensive and

‘E-mail: 290063075@qq.com, xiaowenbo1560@sina.com; phone 860791 8395-3472; fax 860791 8395-3472;

14th Conference on Education and Training in Optics and Photonics: ETOP 2017, edited by Xu Liu,

Xi-Cheng Zhang, Proc. of SPIE Vol. 10452, 104526S · ( 2017 ICO, IEEE, OSA, SPIE

CCC code: $0277-786 X / 17 / \$ 18 \cdot$ doi: $10.1117 / 12.2270039$

Proc. of SPIE Vol. 10452 104526S-1 
innovative experiments lay a solid foundation for students. On the method, we first find problems according to difficulties of daily life and innovation. Then, we convert these problems into TRIZ standards questions. Finally, we give suitable solutions for themselves by using common TRIZ method. The process of innovative practice can develop students' innovative thinking and spirit, as well as, capacity for innovation. In the project, we seek technology breakthrough around system design, photoelectric transformation efficiency and flight power of solar unmanned aircraft. Among them, the method runs through creative and innovative practices, including innovative experiments and solar unmanned aircraft projects. We will give some products of innovation, such as patents, papers and winning competitions. Above all, by training students to grasp core technology of solar unmanned aircraft, we will grow a business based on innovation.

\section{IDEAS OF CREATIVE TRAINING}

The basic idea of reform follows. Based on aircraft features, we will develop aviation project-led and innovationrelated reform. Combined strengthening foundation with enlightening innovation and knowledge, with the activity of science and technology, the creative training of students will last for four years in university. This is a step by step and spiral process.

3.1 Using the systemic analysis method of the creative idea activities and the creative ideas of college students, we develop innovation topic and design based on analysis of innovating rules and solve innovative problems by using the creative method.

TRIZ runs all through college years by ongoing guiding innovation. In the aspect of innovative training, the students will receive an education of TRIZ creative method and visit TRIZ innovation association and innovation activities when they first come to college. In addition, we opened some elective courses for all students, such as Theory and Application of TRIZ Innovation and Innovation, Patents and Competitions Guidance. These courses lead students to decide innovation topics of the physic experiments organize teams of innovation projects and develop innovation practices. Based on innovation practices, students can make creative work, apply for patents and participate in competitions.

\subsection{Guiding by aircraft feature projects develops the capacity for innovation.}

Students have active innovation ideas and spark innovation by training of TRIZ creative method. Based on the creative training on the three-dimensional and comprehensive platform of students' innovation of science and technology, we further guide students to decide innovation project topics by combining aircraft feature and subject area with social needs and personal characteristics. We also guide students to build or join innovation project team and work in a team according to projects. During innovation process, students are always the main body from selecting topics to finishing projects, including patent filing and competition.

\subsection{Building innovation team by using the idea of TRIZ super system and developing innovation practice.}

Multiple cross-department and cross-grade synthetic innovation teams of science and technology are built around a series of innovation projects by using ideas of TRIZ super systems, which realized echelon combination of students with different majors and practices. Teachers guide team members' self-learning and research. Self-earning and research include joining technological innovation month with every summer holiday under teachers' guidance and regular a series of training of technology base. Team members with diverse backgrounds learn from each other and focus on the subject of specific innovation projects. Students can quickly grasp basic techniques, methods and advanced technological knowledge of technological innovation and develop a spirit of innovation and teamwork by self-research and learning. For example, the team of multi-disciplinary cooperation by dominating photoelectric subject solved problems on technological frontier of a contemporary model airplane.

\subsection{Innovation platform building}

We have established NCHU training base of Jiangxi innovation method center, college students' TRIZ innovation society and NCHU popular science education base of Jiangxi science and technology association. In addition, we also established only TRIZ innovation method institute in Jiangxi province, which is used to carry out research and appliance of innovation theories and methods. During training of innovation talents, we implement TRIZ innovation method education and explore unique innovation education method of basic experiments. The unique method is based on college physical experiments with innovation method as linkage and can inspire students' innovation ideas and develop students' innovation ability and efficiency. 


\section{TALENT DEVELOPMENT EFFECTIVENESS OF INNOVATIVE EDUCATION MODEL}

After almost 6 years, college students' innovative education model exploration and practice for the photoelectric major by guiding TRIZ have taken good effect. Almost 80 teachers and 3220 students benefit from the exploration and practice. The students regard that the innovative education model and practice inspired their innovative ideas and developed their innovative ability. They have great teamwork and innovative spirit to the practice. The innovative works, patents and prize certificates of competitions improved the content of college students' science and technology innovation and provided potent proof for their ability, which greatly increased employment and employment levels of students. The employers generally reflect that these students can quickly contribute to the technological innovation of enterprise with learning fast and strong innovative ability. It is easier that students pass interview for post graduate education successfully when they show their finished innovative projects and achievements, which is different from the past. In the past, the candidate of ordinary universities is easily eliminated, when they went for the interview of key universities. Instructors like to recruit these students with strong innovative ability, because they can quickly move into role and take research project.

The training of the innovative education model and innovative platform greatly improved innovative ability of college students and developed a large pool of innovative talents.

(1). The solar-powered plane which is developed by the team of solar lab won the innovation award of national model aircraft competition in 2009, which is the first solar-powered plane of national innovation competition on model aircraft. From 2011, the national model aircraft championship has specific competition of solar-powered plane every year.

(2). In 2011, the new solar-powered aerial photo plane, which was developed by the cross-disciplinary solarpowered plane of aerial photo team, won the grand prize in the fourth national college student energy-saving emission reduction social practice and science and technology competition. This became a role model of synthetic innovation with air character and cross disciplinary.

\section{SUMMARY}

Guiding by TRIZ, we fused drone competition project, research project and entrepreneurship project, which solved the key problem of creative and innovative education method. Using TRIZ innovative theory, we guided that the college students selected good topic to improve the success rate of creation and innovation by combining special features with a resource.

\section{ACKNOWLEDGEMENT}

This work was in part supported by Teaching Research Project of Computing Physics Course in higher education (JW-15-JW-02), Nanchang Hangkong University teaching reform project (JY1460), Research and Practice on Training of Students' Innovative Spirit and Innovative Practice Teaching Link in the Electronic Science and Technology Major (JXJG-09-7-20), Research and Practice on Training of Innovative Ability of College Students Based on TRIZ Theory (JXJG-15-8-12), TRIZ Innovative Method and Application (JY1526), Practice on Research of Nano Material Properties by Using Computational Physics (JZW-16-JW-01).

\section{REFERENCES}

[1] ZHANG Jianwei, REN Yongcan, ZHAO Hui. The Theoretical Exploration and Training Path of Team Scientific Creativity among Science and Engineering Undergraduates - The Mode and Enlightenment of the Experimental Based on Optoelectronics Innovation Education in Beijing Institute of Technology. Modern Education Science, 2016, 11:74-80.

[2] Hu Minqiang, Wang Enrong, Yan Wei, etal. The electrical specialty construction based on innovative education as the starting point. China University Teaching, 2015, 11:44-47.

[3] WANG Xiao-di, WANG Song-wu, LI Hai-po. Innovative Education and Educational Innovation. Research and exploration in laboratory, 2013, 6:283-286.

[4] http://www.gov.cn/zhengce/content/2015-05/13/content_9740.htm 
[5] Xu Chunmei, Zhang Shao, Liu Bingqi, etal. Cultivating Innovative Consciousness in the Teaching of Optoelectronic Engineering. Education Teaching forum, 2016,14:88-90.

[6] Zhang Liuyang, Huang Jinzhe, Shen Tao, etal. Research on the Model of Photoelectric Design Competition with Full Participation in Polytechnic University. University Education, 2016,7:126-127.

[7] http://service.law-star.com/cacnew/200807/130020236.htm. 